\title{
Genotoxic Effects on buccal Cells of Workers Exposed to Fogging Sprays during Fogging Operation
}

\author{
Normah Awang*1, Dg Noor Aisah Kismin ${ }^{1}$, Nurul Farahana Kamaludin ${ }^{1}$ and Ahmad Rohi bin Ghazali ${ }^{2}$ \\ ${ }^{1}$ Environmental Health and Industrial Safety Programme, Malaysia
}

${ }^{2}$ Biomedical Science Programme, Universiti Kebangsaan Malaysia, Malaysia

Received: October 05, 2017; Published: October 12, 2017

*Corresponding author: Normah Awang, Environmental Health and Industrial Safety Programme, Faculty ofHealth Sciences, Universiti Kebangsaan Malaysia, Jalan Raja Muda Abdul Aziz, 50300 Kuala Lumpur, Malaysia

\begin{abstract}
Background: Genetic damage is one of the most fundamental causes of structural and functional changes in DNA. There are a great number of physical, chemical, and biological agents that, either directly or indirectly, damage the integrity of this macromolecule. Genetic damage may be caused by environmental exposure to genotoxins, radiations, chemicals, micronutrient deficiency, lifestyle factors, and genetic factors.

Methodology: Analysis of micronucleus in buccal cells is used to study the genotoxic effect on workers exposed to fogging sprays during fogging operation. In this study, buccal cells from 31 fogging workers and 24 office workers were collected. The former was the exposed group, while the latter was the control group. The respondents were also required to answer a questionnaire. DNA damage was scored by counting the frequency of micronucleus per 1,000 cells for each sample. Scoring was done by observing the formation of micronuclei after staining using acridine orange.
\end{abstract}

Results: The result showed that the frequency of micronucleus in the fogging workers was significantly higher than the office workers. Other factors affecting the formation of micronuclei, such as age, smoking status, and years of pesticide exposure, was also investigated in this study. The results proved that there was a significant difference in the frequency of micronucleus among the workers who smoked and workers who did not smoke in the exposed group. In contrast, there were no significant differences for the factors namely age and years of pesticide exposure. There was also a weak positive correlation between working period (years) with the frequency of micronucleus, with $\mathrm{r} 2=0.387$, $p<0.05$. Multiple linear regression test also suggested that smoking status and years of pesticide exposure can be the significant predictors for the frequency of micronucleus $(\mathrm{p}<0.05)$.

Conclusion: The genotoxic effect that occurs in fogging workers should be further assessed to improve their health and to maintain the safety at the workplace.

Keywords: Micronucleus Assay; DNA damage; Fogging

\section{Introduction}

The number of death due to dengue fever in Malaysia is at an alarming level with 109 deaths reported from $3^{\text {rd }}$ January 2016 to $14^{\text {th }}$ May 2016 [1]. The Government in collaboration with the Ministry of Health Malaysia have been conducting fogging operation to control the spread of dengue in hotspot areas in Malaysia. Thermal fogging spray is recommended as a control measure to kill the mosquitoes at their adult stage [2]. A few chemicals are frequently used in thermal fogging operations, such asmalathion, fenitrothion, fenthion, and some other pyrethroid pesticides [3]. These pesticides, especially malathion, are associated with a genotoxic effect as they could worsen the damage on chromosomal structure in cells [4]. Research by Koutros et al. [5] also found out that there is an increased and aggressive prostate cancer among workers who use a combination of a few pesticides such as malathion, terbufos, and fonofos.

The mechanism of cancer starts when an individual is exposed to genotoxic agents for a long period of time. This exposure causes chromosomal damage when fragments of chromosomes do not move to the opposite pole during anaphase stage. The nuclear membrane forms around the chromosomal fragments, which eventually develop into a small-sized nucleus known as a micronucleus (plural: micronuclei). Micronucleus formation is also an indication of an increase in DNA damage, which is often encountered in the formation of cancer cells [6]. To identify the formation of micronuclei in cells, micronucleus assay method is used. There are two types of cells that can be used for this method, 
namely lymphocytes and buccal cells. However, sampling of buccal cells is preferable because it is easier and cheaper than using lymphocytes and causes no pain to the subject [7].

The aim of this research was to study the genotoxic effect in terms of micronucleus formation among fogging workers due to the exposure to fogging chemicalsat which previous studies have found that the effect can be seen on the farmers who handle pesticides to kill the insects and pests. This study reveals new findings in which there were no previous studies that examined the effect on fogging workers. The results are reported in this article by comparing the frequency of micronucleus per 1,000 cells between fogging workers and office workers. Several factors that may potentially contribute to the formation of micronucleus, such as age, smoking status, and years of pesticide exposure were also investigated.

This research study has proven that there is DNA damage that can be seen in the spraying operation workers exposed to genotoxic agents through the formation of micronuclei in their buccal cells. In addition, the findings also prove that there are no significant differences to differentiate between categories of age and duration of pesticides exposure to the fogging workers. Only smoking status that showed a significant difference to distinguish the two groups of workers who smoke and workers who do not smoke.

\section{Materials and Method}

Materials: Chemicals: Acetic acid, $0.0025 \%$ acridine orange (AO), $0.03 \mathrm{M}$ ethylene di amine tetra acetic acid (EDTA), 1\% of dimethyl sulphoxide (DMSO), methanol, $0.075 \mathrm{M}$ potassium chloride (KCl), 0.64 M sodium chloride ( $\mathrm{NaCl}$ ), $0.01 \mathrm{M}$ Tris- $\mathrm{HCl}$.

Distribution of Questionnaires: The questionnaire, which was a modified version of the questionnaire from Program Molek Tani KPKK UKM 2014/2015, was distributed to the subject before collecting the buccal cells. The respondents' sociodemographic data, disease history, employment background, type of mosquito pesticides used, smoking status, and type of personal protective equipment worn during fogging operation were collected using the questionnaire.

Collection of Buccal Cells: Before taking the sample, the subjects were asked to wash their mouth with water to remove any contaminants or food residuals. Buccal cells were collected by gently scrapping the mucosal surfaces on both sides of the cheek using a sterile wooden tongue depressor [8]. This process was carried out for a minute to obtain adequate buccal cells from each subject. The buccal cells collected were then transferred into polypropylene tubes containing $5 \mathrm{~mL}$ of buffer solution. Each tube was then labelled with the name of the subject.

Fixation and Sample Processing: Buccal cells were washed 3 times in a buffer solution (0.03 M EDTA, 0.01 M Tris-HCl, 0.64 M $\mathrm{NaCl}$ ) at $\mathrm{pH} 7$ by centrifugation at 2,000 rpm for $10 \mathrm{~min}$. For each of the last wash, the cell pellet was added with $5 \mathrm{~mL}$ of $0.075 \mathrm{M} \mathrm{KCl}$ and $50 \mathrm{~mL}$ of $1 \%$ DMSO. The compounds were then incubated for $30 \mathrm{~min}$ at room temperature and then added with Carnoy solution (methanol and acetic acid at a ratio of 3:1). The compounds were centrifuged again at $2,000 \mathrm{rpm}$ for $10 \mathrm{~min}$. The supernatant was then removed, and the cell pellet was added with Carnoy solution and stored at $-20^{\circ} \mathrm{C}$ for subsequent analysis.

Preparation and Staining of Slides: The cell pellet was washed twice with Carnoy solution at 2,000 rpm for $10 \mathrm{~min}$. At the last wash, the supernatant was removed, and $1 \mathrm{~mL}$ of the remaining solution was left in the tube. $200 \mathrm{~mL}$ of cell suspension was dropped on the slide that had been heated and cleaned. The slides were then allowed to dry for 5-10 min and stained using $0.0025 \%$ acridine orange (AO) for microscopic analysis. The slides can be stored in a dry slide storage box and stored in a refrigerator with a temperature of less than $4^{\circ} \mathrm{C}$ [9]. Staining process was done in a dark room because acridine orange is very sensitive to light. A total of three replicates of cells were prepared for each sample to obtain the average number of micronuclei formed per 1,000 cells.

Scoring of Micronucleus per 1,000 Cells: The presence of micronucleus was observed by using a fluorescent microscope at $200 \times$ and $400 \times$ magnifications. Several criteria were considered in the scoring, as stated by Bonassi et al. [10]. For the first criterion, the cells with the presence of major and minor nucleus were recognised as micronucleus. The micronucleus was round or oval and had a diameter 3-16 times smaller than the size of the main nucleus. Most cells had only one micronucleus, but it was possible to have more than one micronucleus in one cell. This situation could be seen in subjects who had been exposed to genotoxic agents or radiation in a long term. Micronucleus should also be located in the cytoplasm of the cell. The pattern and colour intensity of the chromatin must also be the same as the main nucleus. Last criterion was that the border must be clearly seen to prove the presence of the nuclear membrane.

\section{Results and Discussion}

The frequency of micronucleus per 1,000 cells was recorded as a percentage (\%) and expressed as mean \pm Standard Error Mean (SEM) for three replicates of the samples $(n=3)$. The sample size for the exposed group and the control group was less than 100 . Therefore, Shapiro-Wilk test was chosen to test the normality of the data distribution for the frequency of micronucleus.

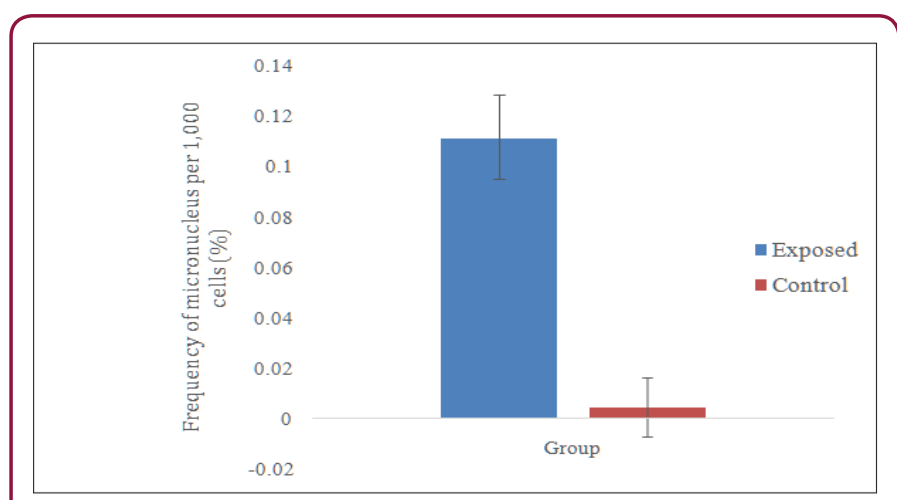

Figure 1: Comparison on micronucleus frequencies between fogging workers (exposed) and office workers (control). 
Data distribution was not normal; therefore, Mann-Whitney test was used to compare the frequency of micronucleus between the exposed group and the control group. Figure 1 shows the micronucleus frequencies in the exposed group $(0.1117 \pm 0.0167)$, which was significantly higher $(\mathrm{p}<0.001)$ compared to the micronucleus frequencies in the control group $(0.0047 \pm 0.0117)$. This result was also reflected in the study by Garaj-Vrhovac [11] involving 10 workers involved in the manufacturing of pesticides and 20 control workers who were not directly involved in the production of pesticides. The study found out that there was a significant difference in the micronucleus frequency in both groups, indicating that exposure to pesticides increased the formation of micronucleus in the buccal cells.

Data distribution was not normal; therefore, Mann-Whitney test was used to compare the frequency of micronucleus by age category in the exposed group. The range for the age was 28-39 years old. The median value (32 years) was taken as the midpoint to distinguish between these two age categories. Figure 2 shows the micronucleus frequency for the exposed groups aged $\leq 32$ years $(0.1044 \pm 0.0190)$, which was slightly lower compared to the group aged $>32$ years $(0.1253 \pm 0.0273)$. However, the mean values between these two groups were not statistically different. This may be due to the small range of age between 28 and 39 years old, leading to a relatively weak statistical power analysis, thus making it difficult to observe the difference between these two age categories. These findings are also supported by Remor et al. [12] who found out that there was no statistically difference between the groups aged $\leq 38$ years and $>38$ years.

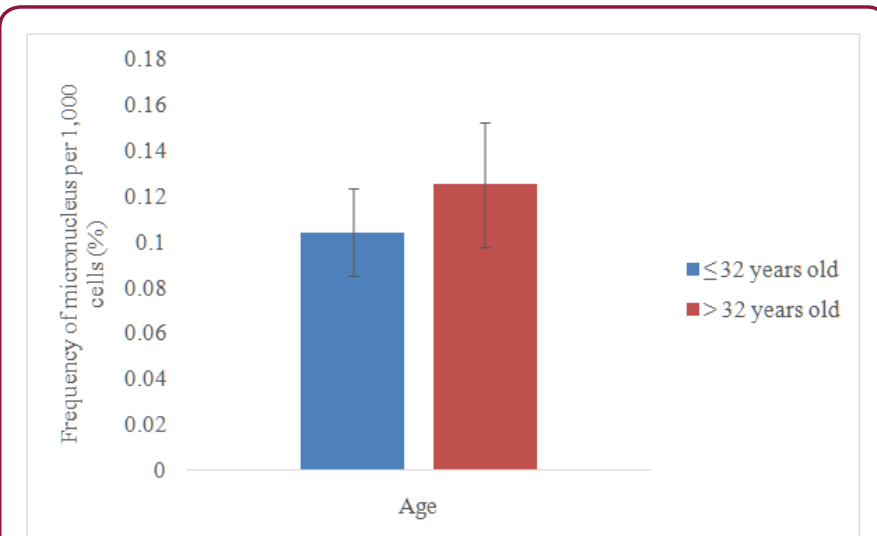

Figure 2 : Comparison between two age categories in the exposed group.

Data distribution was not normal; therefore, Mann-Whitney test was used to compare the frequency of micronucleus by smoking status. Figure 3 shows the micronucleus frequency in the smoker group $(0.1383 \pm 0.0195)$, which was significantly higher $(\mathrm{p}<0.05)$ than the non smoker group $(0.0954 \pm 0.0075)$. This result was supported with the study conducted by Sarto et al [13] who found that workers who smoked had a two-time higher micronucleus frequency than the workers who did not smoke. The study by Bhalli et al [14] also shows that smoking is an additional factor, other than exposure to pesticides that enhances the formation of micronuclei in buccal cells.

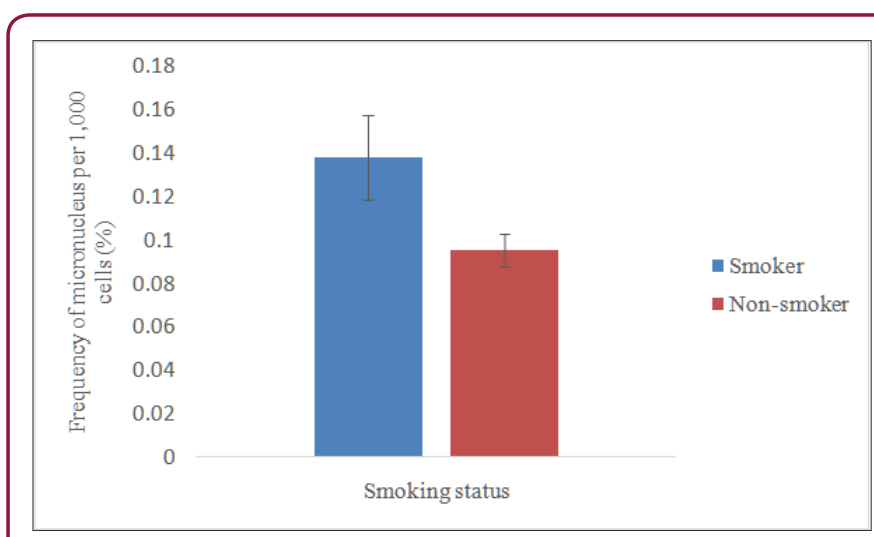

Figure 3: Comparison on smoking status between smokers and non smokers in the exposed group.

Data distribution was normal; therefore, independent samples t-test was used to compare the frequency of micronucleus by years of pesticide exposure. The range for pesticide exposure was 3-15 years. The median value ( 8 years) was taken as the midpoint to distinguish the two categories namely $\leq 8$ years and $>8$ years. Figure 4 shows the micronucleus frequency among the workers who worked $\leq 8$ years $(0.1060 \pm 0.0232)$, which was lower but not significant $(\mathrm{p}>0.05)$ than the workers who worked $>8$ years $(0.1338$ $\pm 0.0533)$. DNA damage that occurs on buccal cells are associated with continuous use of pesticides. The severity of the damage depends on duration and intensity of exposure [15]. The longer and more frequent is the individual exposed to pesticides, the higher can the formation of micronucleus be found on buccal cells.

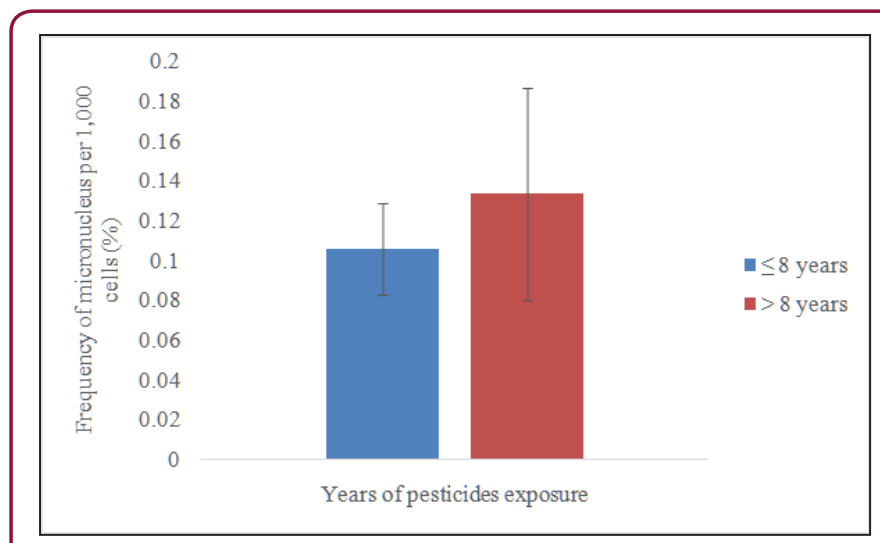

Figure 4 : Comparison between two age categories in the exposed group.

The data distribution was normal; therefore, the data were analysed using Pearson correlation test. The finding indicated that there was a weak positive correlation between the frequency of micronucleus and the working period (years) among the exposed workers (Table 1). This finding supports the claim that the longer is the period of pesticides exposure, the higher is the frequency of micronucleus per 1,000 cells.

Table 2 shows the results for multiple linear regressions to identify the factors influencing the frequency of micronucleus per 1,000 cells. The study found out that smoking status and 
years of pesticide exposure were the significant predictors for the frequency of micronucleus per 1,000 cells, while age did not show any significant correlation. Twenty-six percent of the increase in the frequency of micronucleus per 1,000 cells was influenced by smoking status, while $15 \%$ of the increase in the frequency of micro nucleus per 1,000 cells was influenced by the years of pesticide exposure. In addition, the study also found that a total of $40 \%$ of the change in the frequency of micro nucleus was caused by a combination of three factors namely age, smoking status, and period of work. Next, $60 \%$ of the change in the frequency of micronucleus per 1,000 cells may be due to other factors not examined in this study, such as alcohol consumption, diet, and radiotherapy.

Table 1: Correlation between micronucleus frequency and years of pesticide exposure.

\begin{tabular}{|c|c|c|c|}
\hline & \multicolumn{3}{|c|}{ Frequency of Micronucleus per 1,000 Cells (\%) } \\
\hline & $\mathbf{n}$ & $\mathbf{p}$ & $\mathbf{R}^{\mathbf{2}}$ \\
\hline $\begin{array}{c}\text { Pesticide } \\
\text { exposure } \\
\text { (years) }\end{array}$ & 15 & 0.032 & 0.387 \\
\hline
\end{tabular}

Table 2: Result for analysis of multiple linear regression.

\begin{tabular}{|c|c|c|c|c|c|}
\hline Model & Variable & $\mathbf{R}^{2}$ & $\mathbf{d f}$ & $\mathbf{F}$ & $\mathbf{p}$-value \\
\hline 1 & Age & 0.041 & $(1,30)$ & 1.252 & 0.272 \\
\hline 2 & $\begin{array}{c}\text { Smoking } \\
\text { status }\end{array}$ & 0.260 & $(1,30)$ & 9.995 & 0.004 \\
\hline 3 & $\begin{array}{c}\text { Pesticide } \\
\text { exposure }\end{array}$ & 0.150 & $(1,30)$ & 5.103 & 0.032 \\
\hline & $\begin{array}{c}\text { Age, } \\
\text { smoking } \\
\text { status, } \\
\text { pesticide } \\
\text { exposure }\end{array}$ & 0.400 & $(3,30)$ & 6.011 & 0.003 \\
\hline
\end{tabular}

\section{Conclusion}

This study has proven that there was a significant difference in the micronucleus frequency per 1,000 cells between the fogging workers and the office workers. The findings also proved that there were no significant differences to differentiate the categories in terms of age and years of pesticide exposure. Only smoking status showed a significant difference to distinguish smokers and nonsmokers in exposed group of workers. This research also suggested that smoking status and years of pesticide exposure can be the significant predictors in determining the frequency of micronucleus per 1,000 cells.

\section{Acknowledgement}

We would like to thank Dewan Bandaraya Kuala Lumpur (DBKL) for the cooperation given. Technical support from the laboratory assistants of Faculty of Health Sciences University Kebangsaan Malaysia is gratefully acknowledged.

\section{References}

1. Ministry of Health Malaysia. 2016. Maklumat Kes Denggi Terkini. http:// idengue.remotesensing.gov.my/idengue/index.php.html [10 Jun 2016].

2. Moore PD, Patlolla AK, Tchounwou PB (2011) Cytogenetic evaluation of malathion-induced toxicity in Sprague-Dawley rats. Mutation Research/ Genetic Toxicology and Environmental Mutagenesis 725(1): 78-82.

3. WHO. 2003. Space Spray Application of Insecticides for Vector and Public Health Pest Control: A Practitioner's Guide. Geneva: World Health Organization.

4. Ranson H, Burhani J, Lumjuan N, Black W C (2010) Insecticide resistance in dengue vectors. TropIKA net 1(1): 0-0.

5. Koutros S, Freeman LEB, Lubin JH, Heltshe SL, Andreotti G, et al. (2013) Risk of total and aggressive prostate cancer and pesticide use in the Agricultural Health Study. American Journal of Epidemiology 177(1): 59-74.

6. Luzhna L, Kathiria P, Kovalchuk O (2013) Micronuclei in genotoxicity assessment: from genetics to epigenetics and beyond. Frontiers in Genetics 4.

7. Torres-Bugarín, O, Zavala-Cerna MG, Nava A, Flores-García A, RamosIbarra (2014) Potential Uses, Limitations, and Basic Procedures of Micronuclei and Nuclear Abnormalities in Buccal Cells. Disease Markers.

8. Titenko-Holland N, Jacob RA, Shang N, Balaraman A, Smith MT (1998) Micronuclei in lymphocytes and exfoliated buccal cells of postmenopausal women with dietary changes in folate. Mutation Research/Genetic Toxicology and Environmental Mutagenesis 417(2): 101-114.

9. Pastor S, Creus A, Parro'n T, Cebulska-Wasilewska, A Siffel, et al. (2003) Biomonitoring of four European populations occupationally exposed to pesticides: use of micronuclei as biomarkers. Mutagenesis18 (3): 249 $-258$.

10. Bonassi S, Fenech M, Lando C, Lin YP, Ceppi M, et al. (2001) Human Micronucleus Project. Environmental and Molecular Mutagenesis 37(1): 31-45.

11. Garaj-Vrhovac V, Zeljezic D (2001) Cytogenetic monitoring of Croatian population occupationally exposed to a complex mixture of pesticides. Toxicology 165(2): 153-162.

12. Remor AP, Totti CC, Moreira, DA Dutra, GP Heuser, et al. (2009) Occupational exposure of farm workers to pesticides: Biochemical parameters and evaluation of genotoxicity. Environment International 35(2): 273-278.

13. Sarto F, Finotto S, Giacomelli L, Mazzotti D, Tomanin R, et al. (1987) The micronucleus assay in exfoliated cells of the human buccal mucosa. Mutagenesis 2(1): 11-17.

14. Bhalli JA, Khan QM, Haq MA, Khalid AM, Nasim A (2006) Cytogenetic analysis of Pakistani individuals occupationally exposed to pesticides in a pesticide production industry. Mutagenesis 21(2): 143-148.

15. Bolognesi C (2003) Genotoxicity of Pesticides: a Review of Human Biomonitoring Studies. Mutation Research/Reviews in Mutation Research 543(3): 251-272. 


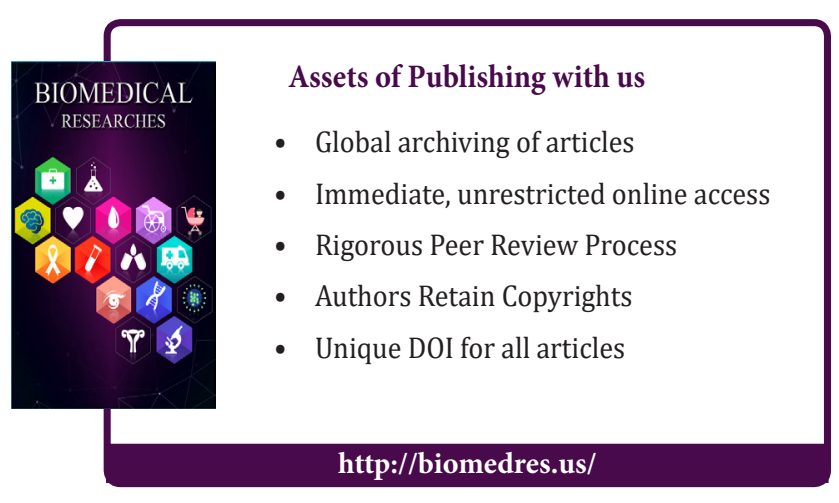

